\title{
Coronary arteriovenous fistula with associated aneurysm
}

\author{
Gautam Sen ำ, ${ }^{1}$ Alice Veitch, ${ }^{2}$ Simon Claridge ${ }^{1}$
}

${ }^{1}$ Cardiology, Salisbury NHS Foundation Trust, Salisbury, UK ${ }^{2}$ Radiology, Salisbury NHS Foundation Trust, Salisbury, UK

\section{Correspondence to \\ Dr Gautam Sen; \\ gautamsen@nhs.net}

Accepted 7 September 2021

\section{DESCRIPTION}

A 56-year-old man was seen in cardiology clinic with exertional chest pain, most marked when walking uphill. He was a heavy smoker but had no other cardiovascular risk factors. His 12-lead ECG was normal, and a CT coronary angiogram (CTCA) was organised with a suspected diagnosis of angina. Echocardiography showed normal cardiac chambers with preserved biventricular systolic function.

The CTCA showed mild coronary artery disease in the distal left main stem and left anterior descending artery (LAD) which was nonobstructive (figure 1). An aberrant vessel arose from the diagonal artery and connected to the main pulmonary artery with evidence of minimal shunting. This vessel was tortuous and contained a small well-defined aneurysmal focus of $3 \mathrm{~mm}$ diameter. A conservative strategy with medical treatment was initiated and his symptoms settled. Follow-up in cardiology clinic over the next year has shown no progression in his symptoms, and cardiac MRI

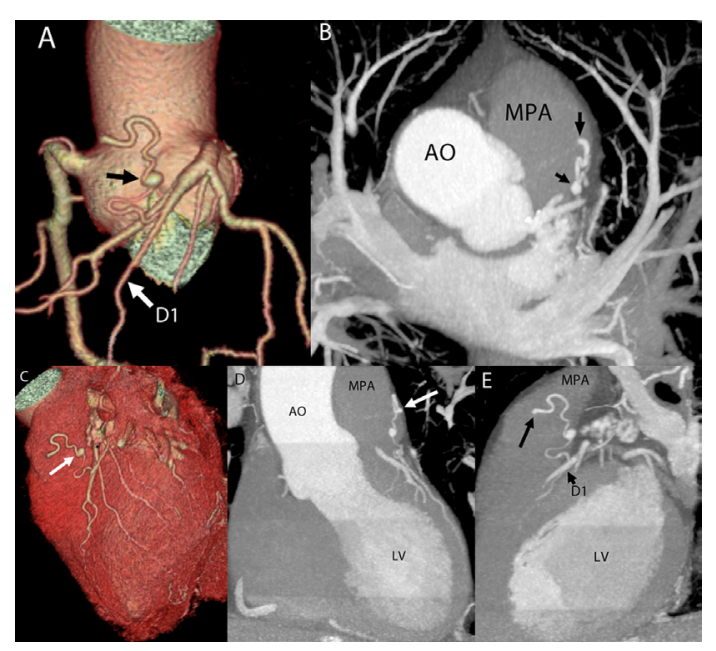

Figure 1 CT coronary angiogram. (A) CT coronary angiogram three-dimensional (3D) tree view demonstrating an aberrant vessel arising from the diagonal artery (D1) with a tortuous bend and passing superiorly. The black arrow shows a small well-defined aneurysmal focus within the vessel. (B, D, E) CT coronary angiogram maximum intensity projections in axial (B), coronal (D) and sagittal (E) views, demonstrating an aberrant vessel arising from the diagonal artery (D1) with a tortuous bend and mid-vessel aneurysm (arrows); connection is seen to the unenhanced MPA with a tiny jet of contrast just visible. (C) The 3D heart reconstruction showing the aberrant vessel arising from D1 with an associated small vessel aneurysm (white arrow). AO, aorta; LV, left ventricle; MPA, main pulmonary artery.

\section{Learning points}

- CT coronary angiography has become the gold standard for defining coronary anatomy; however, its use has led to increased incidence of congenital coronary artery anomalies.

- Coronary artery fistulas are rare congenital anomalies which can cause angina, heart failure and undesirable complications.

- All physicians should be aware of this rare condition, as successful treatment can lead to improvement in symptoms and reduction in morbidity.

has not been organised as there has been no clinical need.

Coronary artery fistulas are rare congenital anomalies ( $\sim 0.9 \%$ of the adult population) which are often discovered incidentally during coronary angiography and increasingly so during CTCA given good anatomical detail obtained. ${ }^{1}$ In rare cases, they can also arise due to iatrogenic reasons. ${ }^{2}$ They may arise from any of the three major coronary arteries; however, the right coronary artery and the LAD are the most common with the circumflex coronary artery rarely involved. ${ }^{3}$ A fistula between the diagonal artery and the main pulmonary artery, as in this case, is a rare finding.

Coronary artery fistulae can present with symptoms of angina, congestive heart failure or arrhythmia. Ischaemia can occur due to the coronary steal phenomenon where blood is shunted away from coronary beds to the low-pressure pulmonary circulation during diastole, resulting in ischaemia in the affected territories. ${ }^{3}$ The main indications for closure of coronary fistulas are clinical symptoms, particularly heart failure and myocardial ischaemia, and in asymptomatic patients with highflow shunts, to prevent the occurrence of undesirable complications.

Treatment options include surgical repair and catheter embolisation. ${ }^{4}$ In the past, surgical repair was the preferred treatment; however, surgery has been associated with a higher level of fistula recurrence, and for this reason a catheter closure procedure is now the preferred treatment of choice. This procedure is not without risk, hence the conservative approach adopted in our case.

Contributors GS wrote the initial article, and this was reviewed and then edited by AV and SC. All authors have been involved with the care of the patient. All authors confirm that this is an original case report and is not under consideration for publication elsewhere nor has it been previously published. All authors have 
made a valuable and important contribution to the case report, and as such are able to warrant their contribution to the Editor if required. All authors recognise they are responsible for the contents of this case report and have read and approved the manuscript. Written informed consent has been obtained from the patient for this case report.

Funding The authors have not declared a specific grant for this research from any funding agency in the public, commercial or not-for-profit sectors.

Competing interests None declared.

Patient consent for publication Consent obtained directly from patient(s)

Provenance and peer review Not commissioned; externally peer reviewed.

\section{ORCID iD}

Gautam Sen http://orcid.org/0000-0002-9037-0907

\section{REFERENCES}

1 Li N, Zhao P, Wu D, et al. Coronary artery fistulas detected with coronary CT angiography: a pictorial review of 73 cases. Br J Radiol 2020:93:20190523.

2 Saleh Y, Almaghraby A, Hammad B, et al. latrogenic aortocoronary arteriovenous fistula. Neth Heart J 2019:27:110-1.

3 Challoumas D, Pericleous A, Dimitrakaki IA, et al. Coronary arteriovenous fistulae: a review. Int J Angiol 2014;23:1-10.

4 Buccheri D, Chirco PR, Geraci S, et al. Coronary artery fistulae: anatomy, diagnosis and management strategies. Heart Lung Circ 2018;27:940-51.

Copyright 2021 BMJ Publishing Group. All rights reserved. For permission to reuse any of this content visit

https://www.bmj.com/company/products-services/rights-and-licensing/permissions/

BMJ Case Report Fellows may re-use this article for personal use and teaching without any further permission.

Become a Fellow of BMJ Case Reports today and you can:

- Submit as many cases as you like

- Enjoy fast sympathetic peer review and rapid publication of accepted articles

Access all the published articles

- Re-use any of the published material for personal use and teaching without further permission

Customer Service

If you have any further queries about your subscription, please contact our customer services team on +44 (0) 2071111105 or via email at support@bmj.com.

Visit casereports.bmj.com for more articles like this and to become a Fellow 